\title{
Blending type Approximations by Kantorovich variant of $\alpha$-Schurer operators
}

\author{
Nadeem Rao ${ }^{1}$, Pradeep Malik ${ }^{2}$, and Mamta Rani ${ }^{2}$ \\ ${ }^{1}$ Shree Guru Gobind Singh Tricentenary University Faculty of Medicine and Health \\ Sciences \\ ${ }^{2}$ Shree Guru Gobind Singh Tricentenary University
}

July 2, 2021

\begin{abstract}
In the present manuscript, we present a new sequence of operators, i:e:, -Bernstein-Schurer-Kantorovich operators depending on two parameters $2[0 ; 1]$ and $>0$ foe one and two variables to approximate measurable functions on $[0: 1+q] ; q>0$. Next, we give basic results and discuss the rapidity of convergence and order of approximation for univariate and bivariate of these sequences in their respective sections. Further, Graphical and numerical analysis are presented. Moreover, local and global approximation properties are discussed in terms of rst and second order modulus of smoothness, Peetre's K-functional and weight functions for these sequences in dierent spaces of functions.
\end{abstract}

\section{Hosted file}

Schurer stancu operators.pdf available at https://authorea.com/users/423334/articles/528801blending-type-approximations-by-kantorovich-variant-of-\%CE\%B1-schurer-operators

\section{Hosted file}

Schurer stancu operators.tex available at https://authorea.com/users/423334/articles/528801blending-type-approximations-by-kantorovich-variant-of-\%CE\%B1-schurer-operators

\section{Hosted file}

birkjour.cls available at https://authorea.com/users/423334/articles/528801-blending-typeapproximations-by-kantorovich-variant-of-\% CE\%B1-schurer-operators 

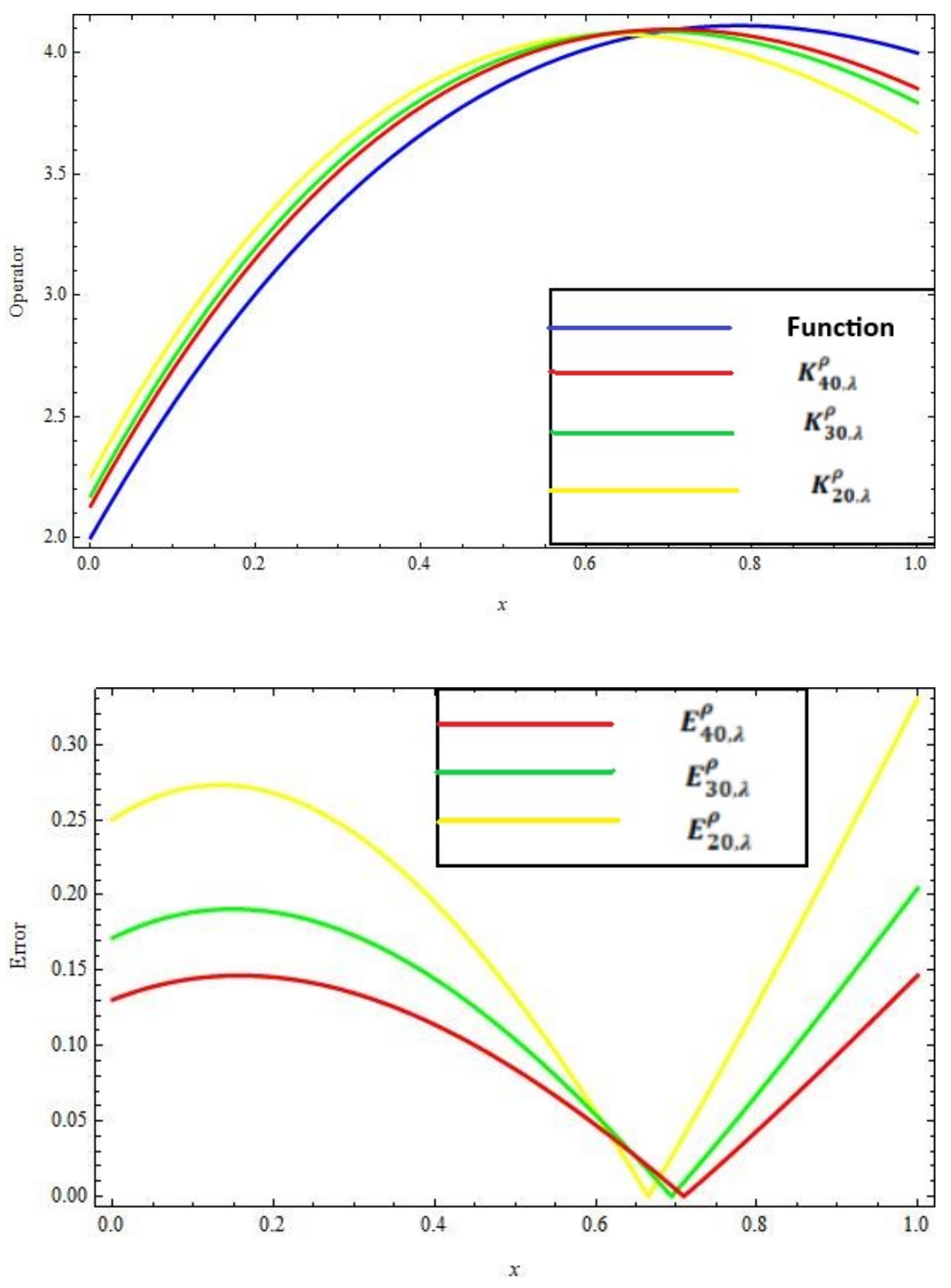


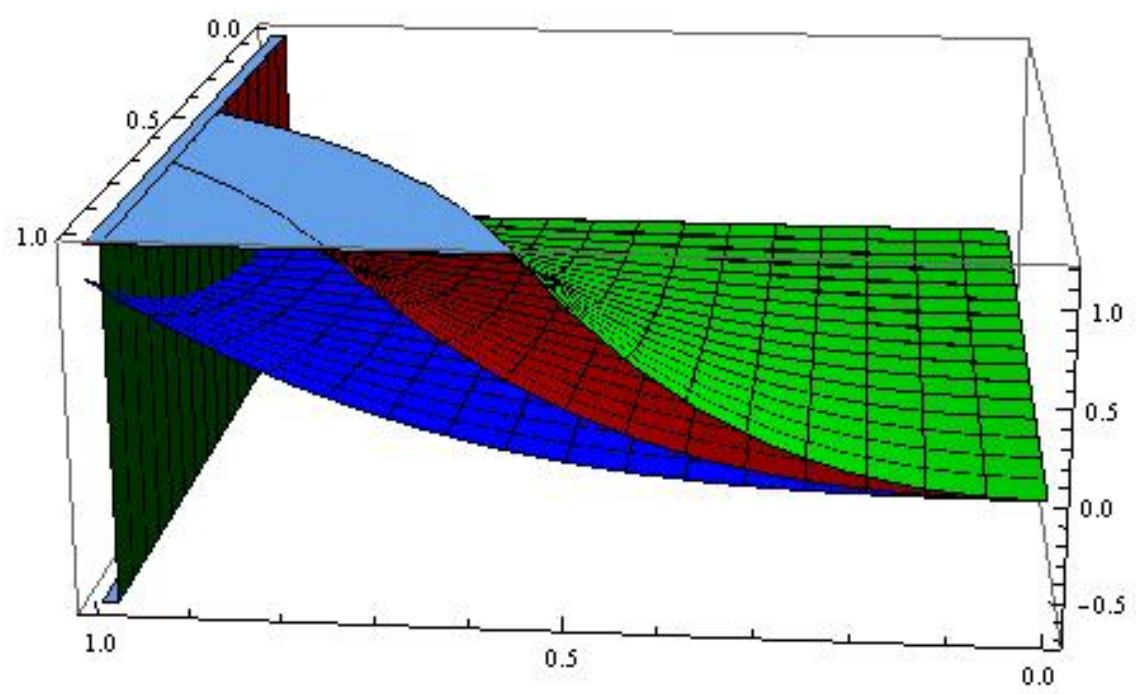

